\title{
ЛАПАРОСКОПИЧЕСКОЕ АОРТО-БИФЕМОРАЛЬНОЕ ПРОТЕЗИРОВАНИЕ У ПАЦИЕНТА С ТРОМБОЗОМ ЭНДОПРОТЕЗА АОРТЫ
}

\section{LAPAROSCOPIC AORTO-BIFEMORAL PROSTHETICS IN A PATIENT WITH THROMBOSIS OF THE AORTIC ENDOPROSTHESIS}

\section{P. Mozgovoi \\ E. Spiridonov \\ V. Mandrikov \\ V. Ufimtsev \\ A. Lukovskova}

Summary. The article presents a clinical case of laparoscopic surgical treatment of thrombotic occlusion of the aortic endoprosthesis. Within 6 months after endoprosthetic repair of infrarenal aneurysm, the patient first suffered a thrombosis of the left branch of the endoprosthesis, in connection with which a cross-femoral bypass of the PTFE prosthesis was performed, and then a thrombosis of the aortic endoprosthesis. The patient was hospitalized urgently with the clinic of acute ischemia of both lower limbs. After appropriate preoperative preparation, the patient underwent laparoscopic aorto-bifemoral prosthetics with the removal of the proximal part of the stent graft and the formation of a proximal anastomosis completely laparoscopically. The postoperative period was uneventful. The patient was rehabilitated as soon as possible. Followup for $\mathbf{4 5}$ months, the aorto-bifemoral prosthesis is functioning, blood circulation of the patient's lower extremities is compensated.

On the basis of our experience we can conclude that laparoscopic surgery techniques can be successfully used for the correction of complications after operations for the abdominal aortic aneurysms.

Keywords: abdominal aortic aneurysm, aorto-femoral bifurcation prosthetics, laparoscopy.
Мозговой Павел Вячеславович

Д.м.н., профессор, ФГБОУВО «Волгоградский Государственный Медицинский Университет»; ФГБОУ ВО «Волгоградский Государственный Медицинский Университет» Минздрава России Клиника № 1,

2. Волгоград

mozgovoypv@mail.ru

Спиридонов Евгений Геннадьевич

К.м.н., дочент, ФГБОУВО «Волгоградский

Государственный Медицинский Университет»; ФГБОУ ВО «Волгоградский Государственный Медицинский Университет» Минздрава России Клиника № 1,

г. Волгоград

seg-s@mail.ru

Мандриков Виктор Викторович

Д.м.н., ФГБОУ ВО «Волгоградский Государственный Медицинский Университет»; ФГБОУ ВО «Волгоградский Государственный Медицинский Университет» Минздрава России Клиника № 1, г. Волгоград zemavic@mail.ru

Уфимцев Владимир Сергеевич Сердечно-сосудистый хирург, ФГБОУВО «Волгоградский Государственный Медицинский Университет» Минздрава России Клиника № 1,

г. Волгоград vovanuf87@list.ru

Луковскова Анастасия Андреевна Сердечно-сосудистый хирург, ФГБОУ ВО «Волгоградский Государственный Медицинский университет» Минздрава России Клиника № 1,

г. Волгоград

luckovskova@yandex.ru

Аннотация. В статье представлен клинический случай лапароскопического хирургического лечения тромботической окклюзии эндопротеза аорты. В течение 6 месяцев после эндоваскулярного протезирования инфраренального отдела аорты по поводу аневризмы пациент перенес вначале тромбоз левой бранши эндопротеза, в связи с чем было выполнено перекрестное бедренно-бедренное шунтирование ПТФЭ протезом, а затем тромб0з эндопротеза аорты. Пациент госпитализирован в срочном порядке с клиникой острой ишемии обеих нижних конечностей I ст. После соответствующей предоперационной подготовки пациенту выполнено лапароскопическое аорто-бифеморальное протезирование с удалением проксимальной части стент-графта и формированием проксимального анастомоза полностью лапароскопически. Послеоперационный период протекал без осложнений. Реабилитация пациента прошла в кратчайшие сроки. Наблюдение в течение 45 месяцев, аорто-бифеморальный протез функционирует, кровообращение нижних конечностей пациента компенсировано. 


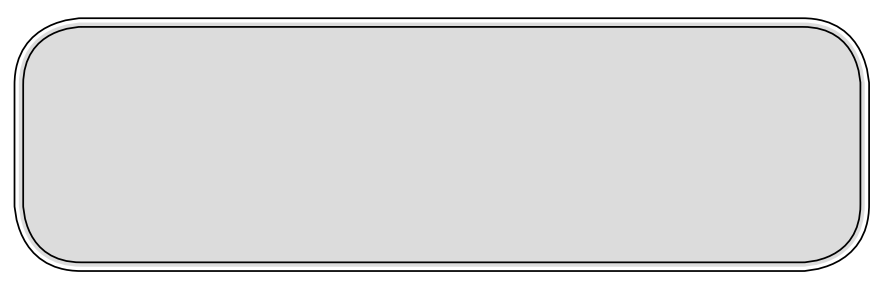

\section{Ввемение}

$\Pi$ о сравнению с открытыми операциями эндоваскулярное протезирование аорты значительно снижает уровень периоперационной летальности и осложнений, что доказано рандомизированными исследованиями $[2,4,6]$. Но процент отдаленных осложнений после эндопротезирования выше: в сроки до 8 лет после первичной операции могут возникнуть как эндолики с ростом аневризмы, так и тромботические осложнения $[1,3,4,5]$. Причем риск тромбоза стент-графта выше чем обычного протеза [3]. Лапароскопические технологии все чаще применяются для коррекции осложнений EVAR, в частности эндоликов $[7,8,9,10]$.

В данной статье представлен случай успешного лечения с помощью эндовидеохирургических методик тромботической окклюзии стент-графта.

\section{Клиническое наблюАение}

Пациент мужского пола, 69 лет, поступил в клинику в срочном порядке с диагнозом: Облитерирующий атеросклероз аорты, артерий нижних конечностей, II А ст. Аневризма инфраренального отдела аорты II типа. Окклюзия левой подколенной артерии. Состояние после эндоваскулярного протезирования аорты от 08.08.14. Тромбоз левой бранши протеза, перекрестное бедренно-бедренное шунтирование протезом ПТФЭ от 18.09.14. Тромбоз эндопротеза аорты, бедренно-бедренного шунта от 01.02.15. Острая ишемия обеих нижних конечностей I ст (по классификации И.И. Затевахина, 2002 г).

В 2014 году пациент перенес эндоваскулярное протезирование инфраренального отдела аорты по поводу аневризмы. Выписан в удовлетворительном состоянии. Через месяц после выписки госпитализирован с тромбозом левой бранши эндопротеза, пациенту выполнена тромбэктомия, и ввиду её неэффективности, перекрестное бедренно-бедренное шунтирование ПТФЭ протезом. Неосложненное течение послеоперационного периода с компенсацией кровообращения нижних конечностей. Через 5 месяцев резкое ухудшение состояния с развитием выраженного болевого синдрома в обеих нижних конечностях. Диагностирована, в том числе по данным компьютерной томографии (рис. 1 и 2), окклюзия эндопротеза аорты, перекрестного бедренно-бедренного шунта.
На основании нашего небольшого опыта можно заключить, что эндовидеохирургические методики могут успешно использоваться для коррекции осложнений после операций по поводу аневризмы абдоминальной аорты.

Ключевые слова: аневризма брюшного отдела аорты, аорто-бедренное бифуркационное протезирование, лапароскопия.

После соответствующей подготовки пациента принято решение о выполнении лапароскопического аорто-бифеморального протезирования.

Под комбинированной анестезией (эндотрахеальный наркоз и перидуральная анестезия) по линии Боброва-Пирогова-Кена осуществлен доступ к бедренным артериям, которые при ревизии проходимы с обеих сторон. После формирования карбоксиперитонеума в брюшную полость в типичных точках введены троакары с инструментами под контролем оптики. По левому боковому каналу, по линии Тольда, отступая от границы с кишечником на 1,5 см, вскрыта париетальная брюшина от уровня селезеночного угла до сигмовидной кишки. Нисходящая ободочная кишка отведена медиально. Мобилизованы левый мочеточник, аорта от уровня почечных артерий до проксимальных отделов общих подвздошных артерий. Определяется спавшаяся аневризма инфраренальной аорты диаметром около 4 см, в просвете стент-графт с тромботической окклюзией аорты на 1 см дистальнее проходимых почечных артерий и на всем протяжении. Аорта тотчас дистальнее почечных артерий пережата эндоскопическим сосудистым зажимом, пересечена поперечно, в просвете расположено основное тело эндопротеза - пересечено, проксимальная часть удалена (рис. 3-6).

Выполнена тромбэндартерэктомия из проксимальной части аорты. Произведено тотальное лапароскопическое наложение проксимального анастомоза между аортой и синтетическим протезом по типу «конец-в-конец» нитью Surgipro3-0 (рис. 7). Запуск кровотока после формирования дистальных анастомозов (рис. 8).

Общая продолжительность операции 280 мин. Время пережатия аорты 100 минут. Время формирования проксимального анастомоза 40 минут. Объем кровопотери 800 мл, реинфузия аутоэритроцитов 530 мл.

Ранний послеоперационный период протекал без осложнений. Пациент был экстубирован через 4 часа после операции. Инотропной поддержки гемодинамики в послеоперационном периоде не требовалось. Кровопотеря по дренажам за сутки составила 80 мл. Через 30 часов после операции пациент был переведен из реанимационного в кардиохирургическое отделение. Переход к жидкой пище на 2-е сутки, к твердой на 4-е сутки после- 


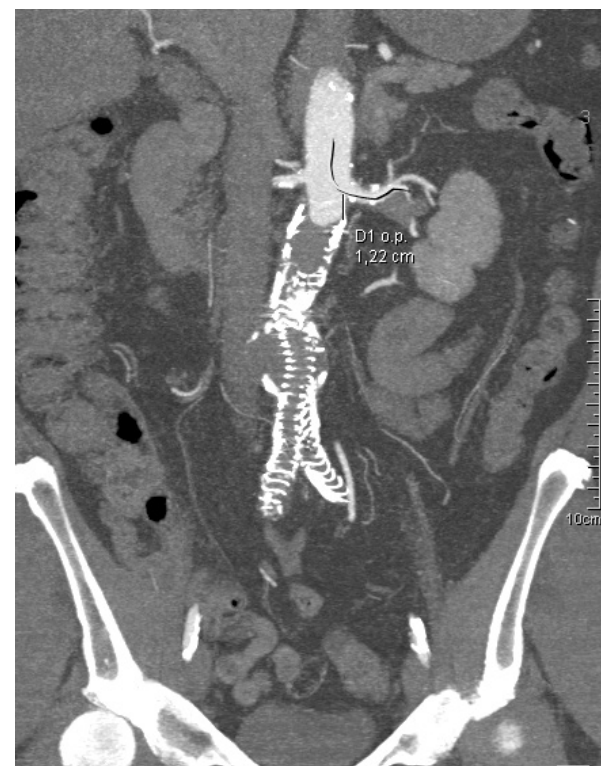

Рис. 1. КТ-аортография пациента при поступлении (окклюзия эндопротеза аорты).

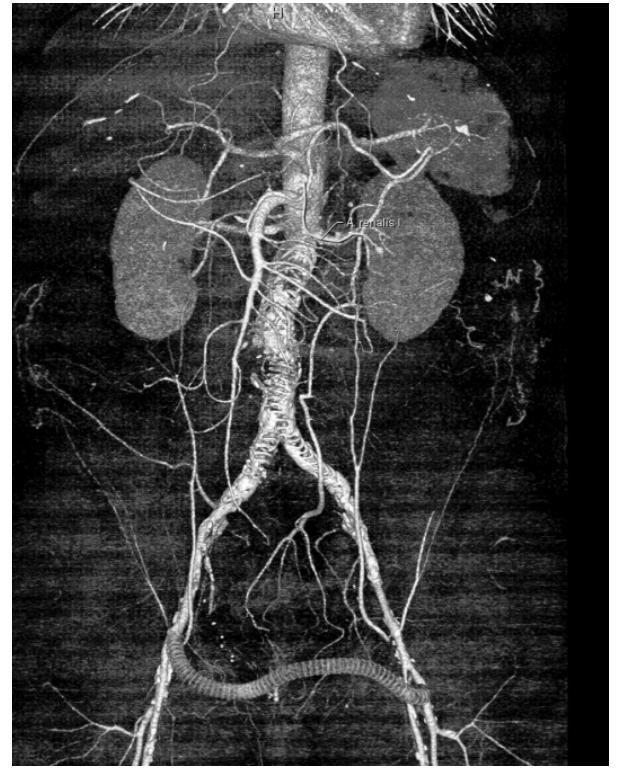

Рис. 2. КТ-аортография пациента при поступлении (окклюзия эндопротеза аорты и перекрестного бедренно-бедренного шунта, 3D реконструкция).

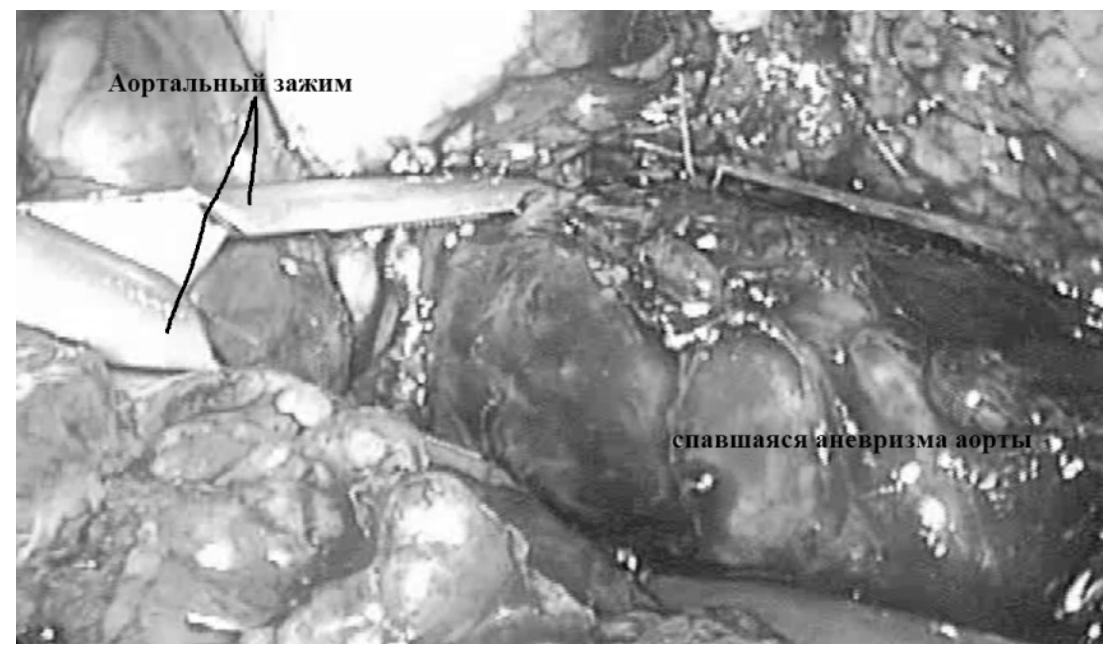

Рис. 3. Выделенная аневризма аорты.

операционного периода. Швы сняты на 7-е сутки послеоперационного периода, заживление послеоперационных ран первичным натяжением. Динамика показателей красной крови на 1-е, 3-и и 7-е сутки послеоперационного периода: $\mathrm{Er}-4,15 \times 10^{12} ; \mathrm{Hb}-122$ г/л; $\mathrm{Er}-3,72 \times 10^{12}$; $\mathrm{Hb}-110$ г/л; Er - 3,64 x 1012; Нb - 110 г/л. На 8-е сутки послеоперационного периода пациент выписан на амбулаторное лечение. Наблюдение в течение 45 месяцев, протез функционирует (рис. 10). Кровообращение нижних конечностей компенсировано. На рис. 9 представлена проксимальная часть эндопротеза аорты.

\section{ОбсужАение}

Проблема повторных вмешательств после хирургического лечения по поводу аневризмы инфраренальной аорты остается актуальной. В течение 2-4 лет уровень выживаемости после эндоваскулярного протезирования аорты и открытых реконструкций выравнивается (89,6\% и $89,7 \%$ соответственно), а уровень отдаленных осложнений, в основном за счет эндоликов и тромботических осложнений, увеличивается $[2,6,9]$. Это обусловливает необходимость постоянного наблюдения 


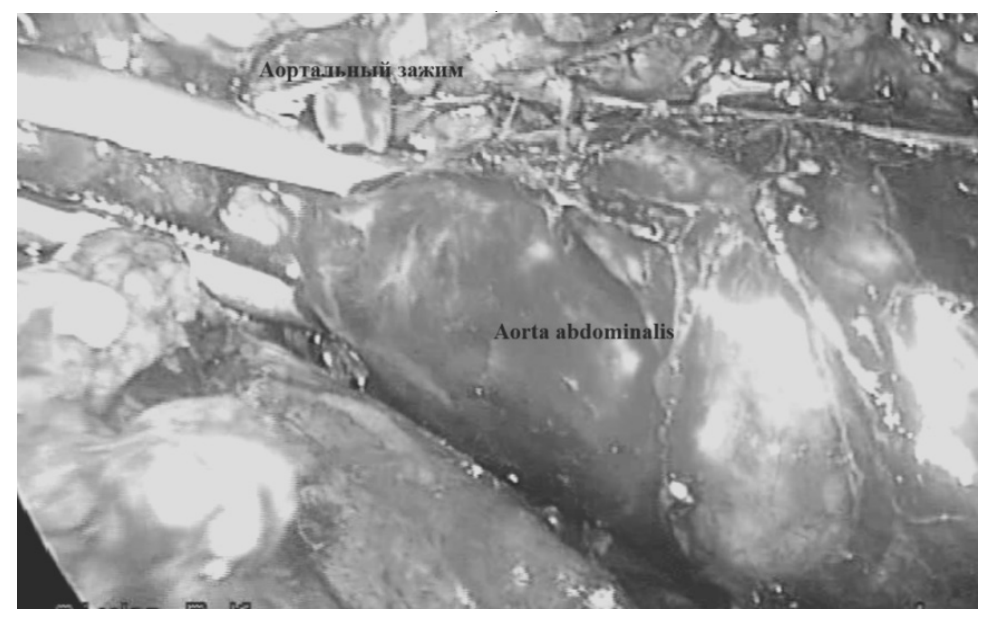

Рис. 4. Пережатие аорты.

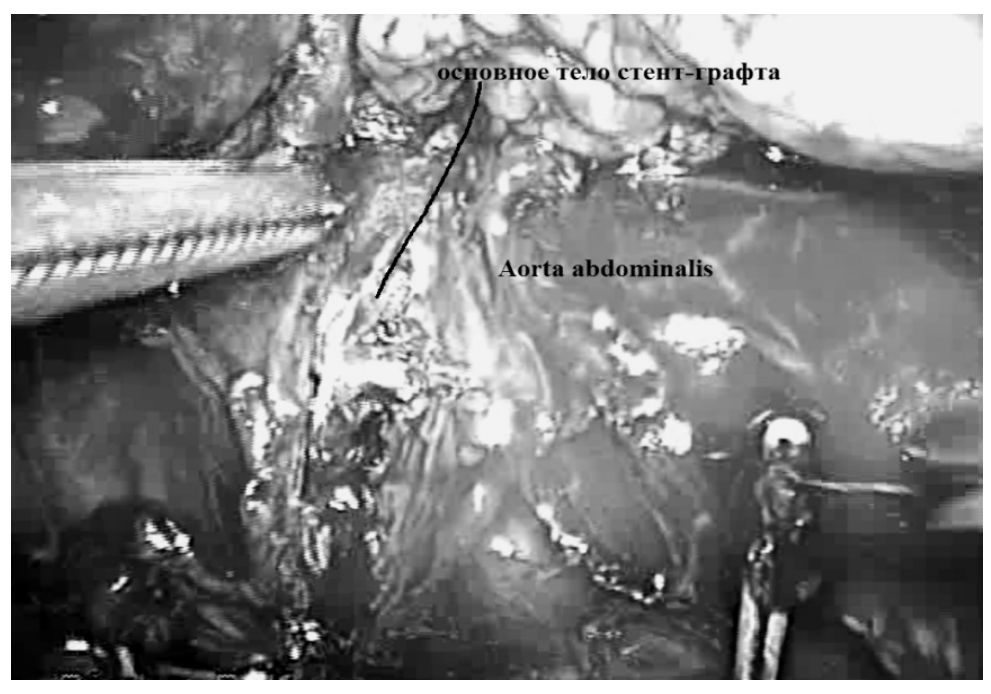

Рис. 5. Аортотомия, в просвете аорты основное тело эндопротеза.

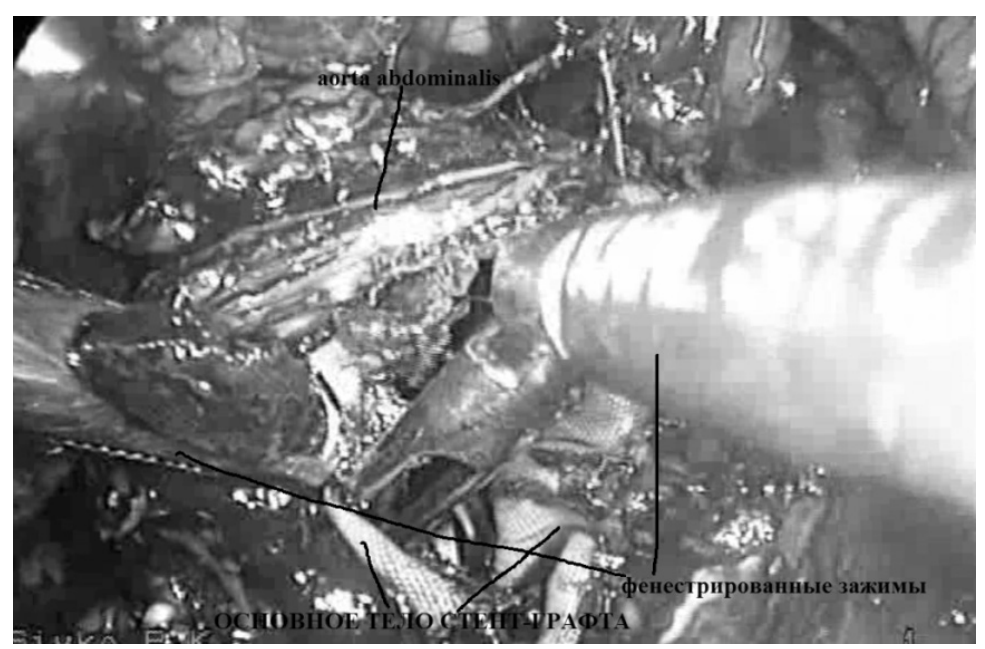

Рис. 6. Удаление основного тела эндопротеза. 


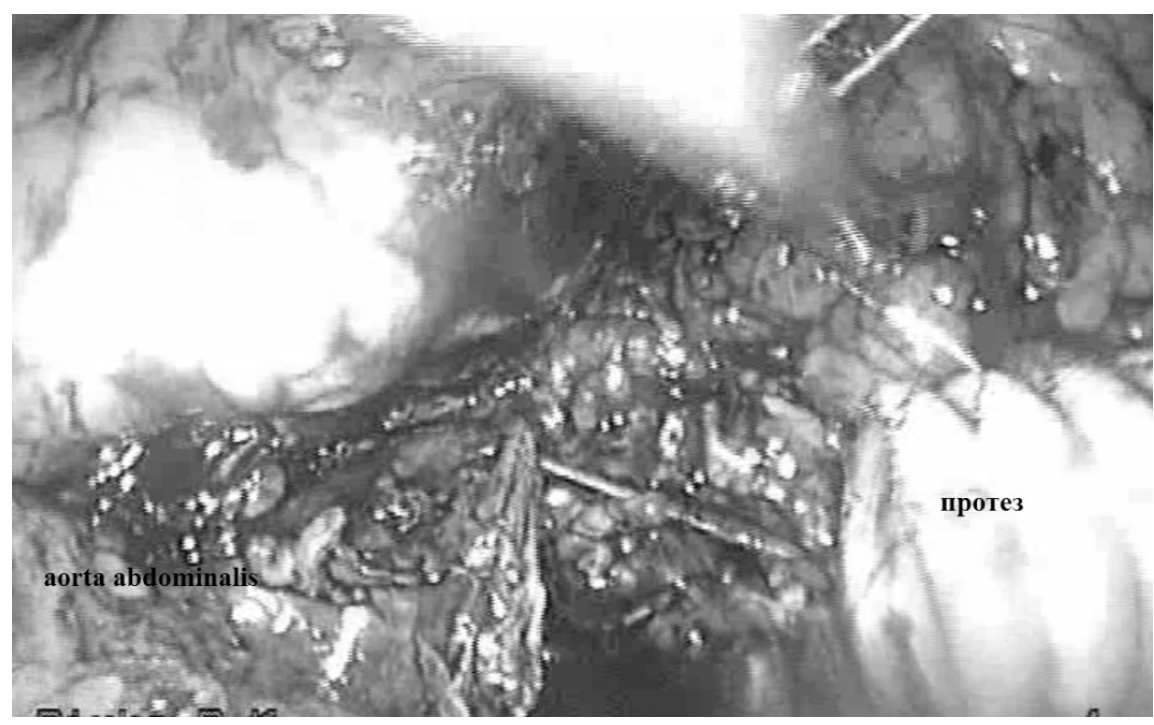

Рис. 7. Формирование проксимального анастомоза.

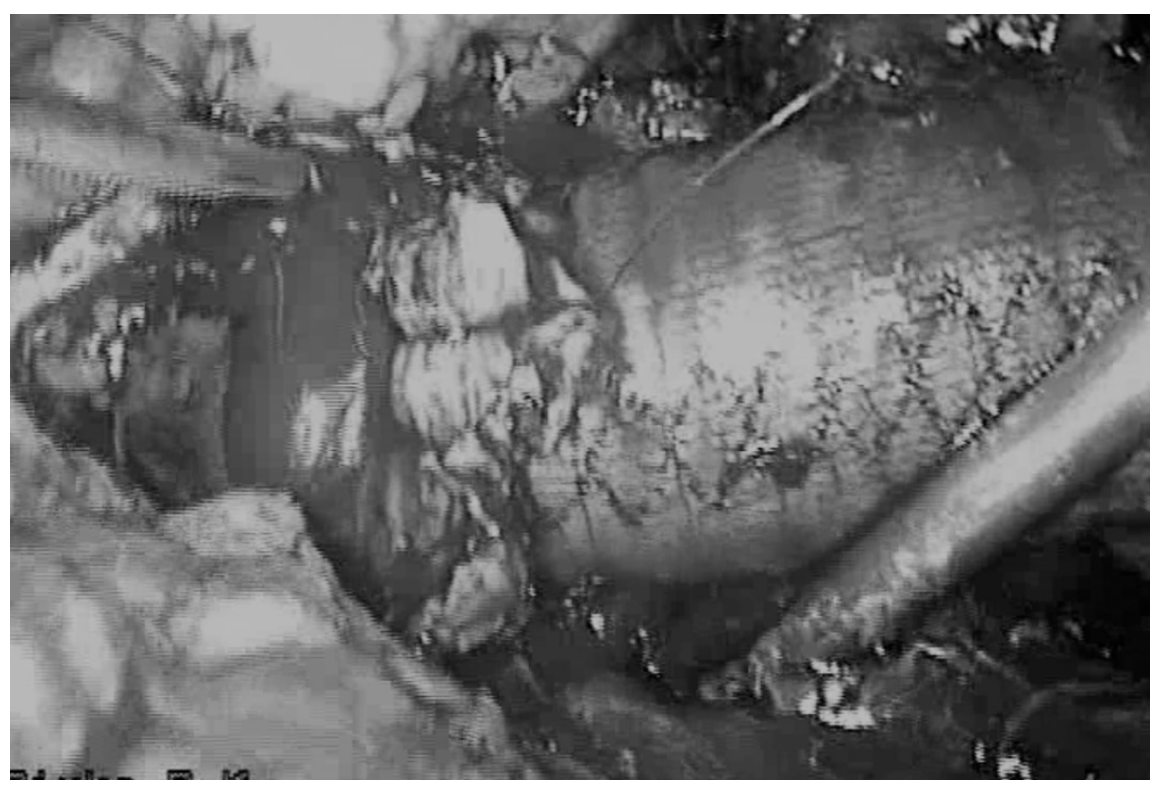

Рис. 8. Запуск кровотока.

пациентов после эндоваскулярного протезирования аорты, и зачастую приводит к выполнению повторных хирургических вмешательств [1, 6, 9]. Таким образом, рентгеноэндоваскулярные методы во многом облегчили проблему лечения аневризм инфраренальной аорты, но не смогли полностью ее решить.

Эндовидеохирургические методики направлены на уменьшение хирургической травмы, оптимизацию течения послеоперационного периода и могут с успехом использоваться не только в качестве первичных хирурги- ческих вмешательств при патологии абдоминальной аорты и ее ветвей, но и в ходе коррекции отдаленных осложнений после эндоваскулярного протезирования аорты [7, 8, 10].

Данный клинический пример демонстрирует, что лапароскопические методики могут успешно использоваться для лечения окклюзионных осложнений после ранее выполненных вмешательств по поводу аневризмы брюшной аорты. Накопление в дальнейшем опыта подобных вмешательств позволит подтвердить данное заключение статистически. 


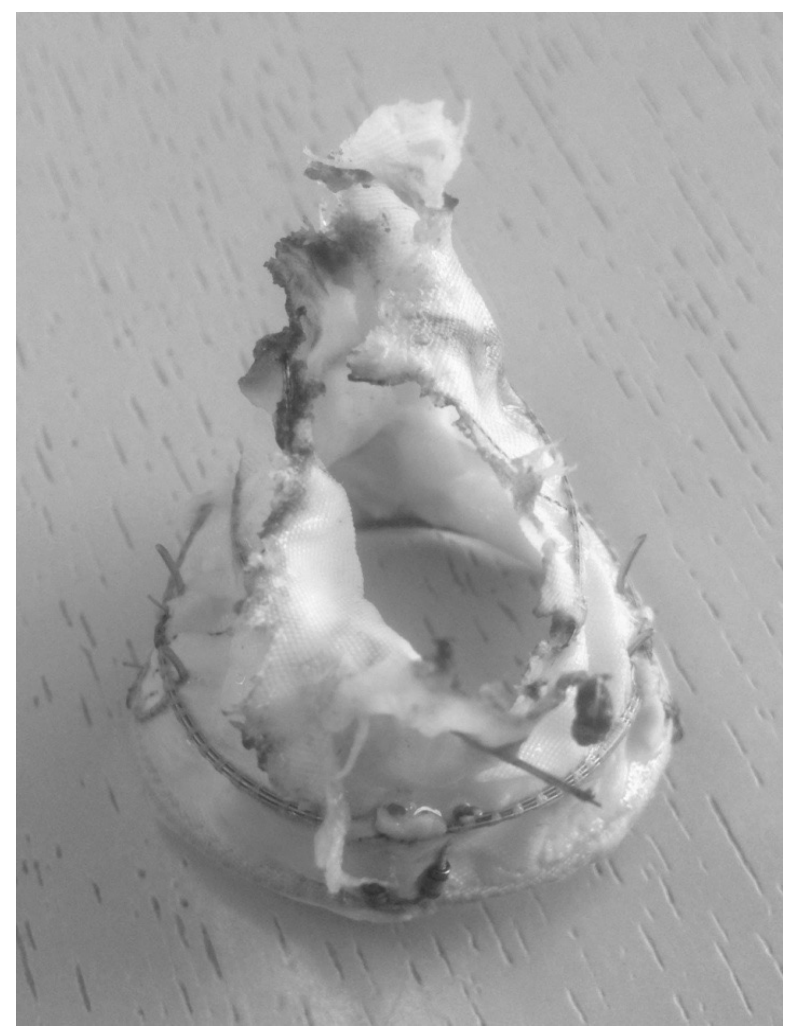

Рис. 9. Фрагмент основного тела стент-графта.

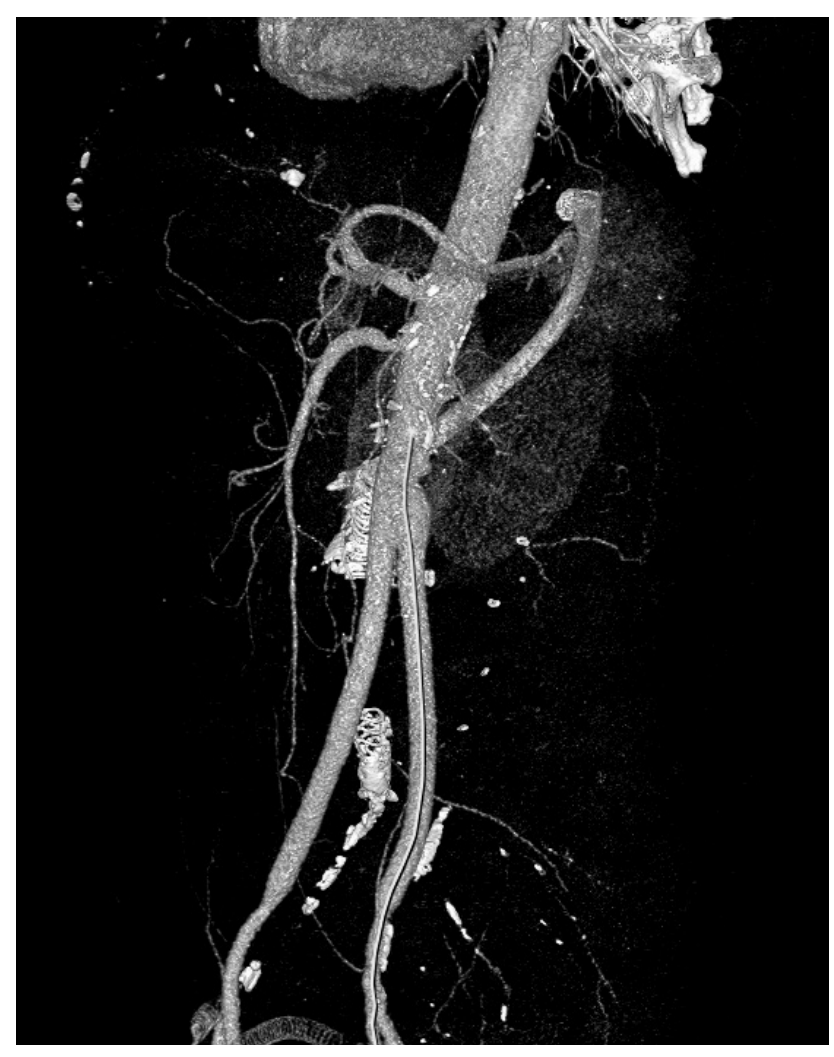

Рис. 10. КТ-аортография через 6 мес после аортобифеморального протезирования (3D реконструкция). 


\section{ЛИТЕРАТУРА}

1. Национальные рекомендации по ведению пациентов с аневризмами брюшной аорты (Российский согласительный документ).- М.: Ангиология ИНФ0, 2012. $-68 \mathrm{c}$.

2. Endovascular aneurysm repair and outcome in patients unfit for open repair of abdominal aortic aneurysm (EVAR trial 2): randomised controlled trial. Lancet. 2005 Jun 25;365(9478):2187-2192.

3. EVAR Trial Participants Endovascular aneurysm repair versus open repair in patients with abdominal aortic aneurysms (EVAR trial 1): randomised controlled trial. Lancet 2005;365:2179-2184

4. Greenhalgh RM, Brown LC, Kwong GP, Powell JT, Thompson SG. Comparison of endovascular aneurysm repair with open repair in patients with abdominal aortic aneurysm (EVAR trial 1), 30-day operative mortality results: randomised controlled trial. Lancet. 2004 Sep 4;364(9437):843-848.

5. Kansal V, Nagpal S, Jetty P. Late Open Surgical Conversion after Endovascular Abdominal Aortic Aneurysm Repair. Eur J Vasc Endovasc Surg (2018) 55, 163-169.

6. Lederle FA, Freischlag JA, Kyriakides TC, Matsumura JS, Padberg FT Jr, et al. For the Open Versus Endovascular Repair (OVER) Veterans Affairs Cooperative Study Group. Long-term comparison of endovascular and open repair of abdominal aortic aneurysm. N Engl J Med 2012;367: 1988-97.

7. Lin JC, Kolvenbach R. Totally laparoscopic explantation of migrated stent graft after endovascular aneurysm repair: a report of two cases JVasc Surg 2005;41:885-8.

8. Touma J, Coscas R, Javerliat I, Colacchio G, Goëau-Brissonnière 0, Coggia M. A technical tip for total laparoscopic type II endoleak repair. J Vasc Surg. 2015 Mar;61(3):817-20.

9. Ultee K.H.J., Büttner S., Huurman R., Gonçalves F. B., Hoeks S. E., Bramer W. M., Schermerhorn M. L., Verhagen Hence J. M. Systematic Review and Meta-Analysis of the Outcome of Treatment for Type II Endoleak Following Endovascular Aneurysm Repair. Eur J Vasc Endovasc Surg (2018) 56, $794-807$.

10. Wee I, Marjot T, Patel K, Bhrugubanda V, Choong AMTL Laparoscopic ligation of Type Il endoleaks following endovascular aneurysm repair: A systematic review. Vascular. 2018 Dec;26(6):657-669.

(c) Мозговой Павел Вячеславович ( mozgovoypv@mail.ru ), Спиридонов Евгений Геннадьевич ( seg-s@mail.ru ),

Мандриков Виктор Викторович ( zemavic@mail.ru), Уфимцев Владимир Сергеевич (vovanuf87@list.ru ),

Луковскова Анастасия Андреевна ( luckovskova@yandex.ru ).

Журнал «Современная наука: актуальные проблемы теории и практики»

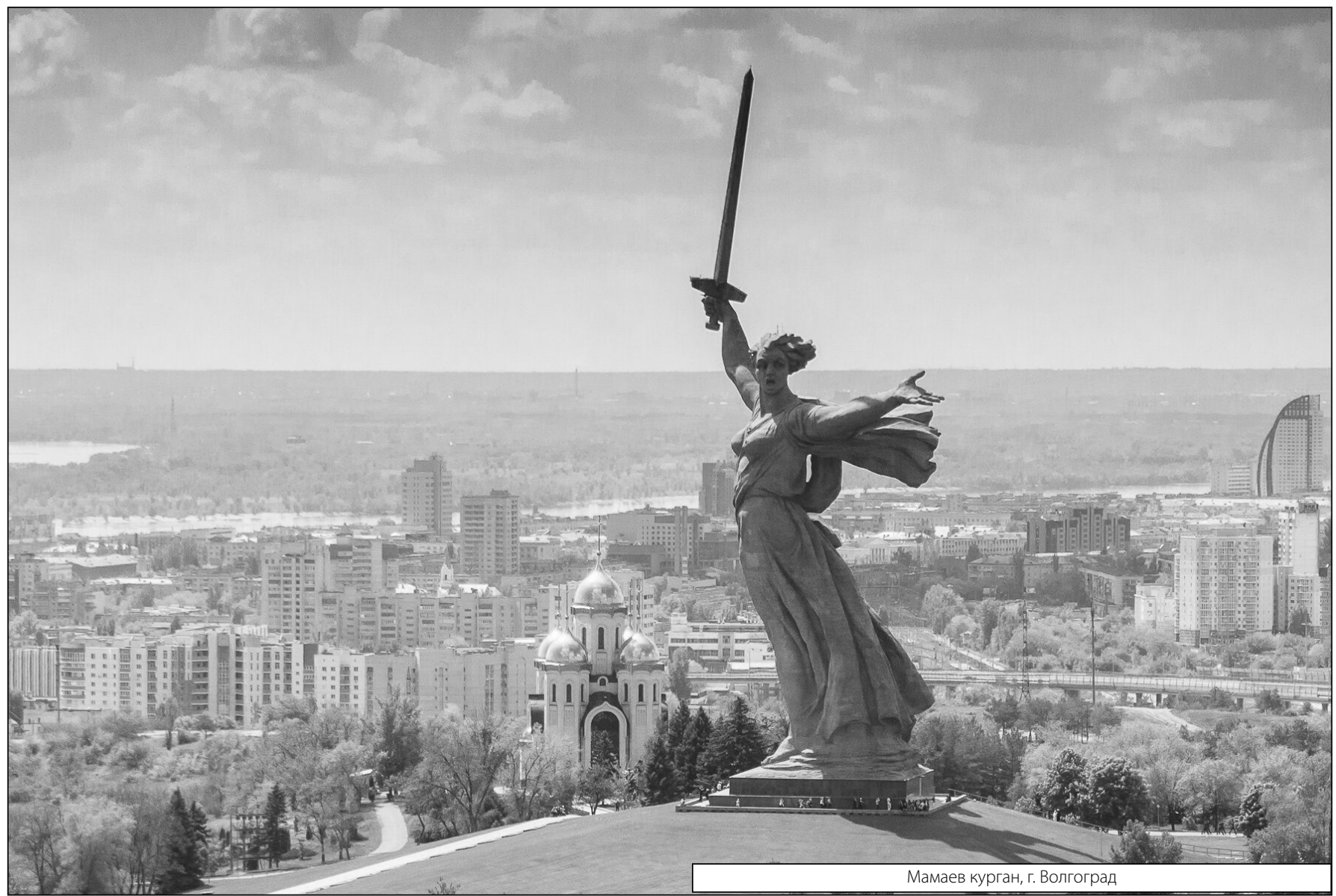

